are arbitrary. So too, in some cases, are the indicators of change. There is, as yet, little scientific evidence to suggest that stabilizing longterm concentrations of carbon dioxide at 350 parts per million is the right target for avoiding dangerous interference with the climate system. Focusing on long-term atmospheric concentrations of the greenhouse gas is perhaps an unnecessary distraction from the much more immediate target of keeping warming to within $2{ }^{\circ} \mathrm{C}$ above preindustrial levels. Nor is there a consensus on the need to cap species extinctions at ten times the background rate, as is being advised.

Furthermore, boundaries don't always apply globally, even for processes that regulate the entire planet. Local circumstances can ultimately determine how soon water shortages or biodiversity loss reach a critical threshold.

Assigning 'acceptable' limits to processes that ultimately determine our own survival is risky in other ways, too. After all, some of the suggested limits may be easier to balance with ethical and economic issues than others. Human interference in the nitrogen cycle may well have damaging long-term consequences, but the production of nitrogen for agriculture has also fed large parts of humanity.

But even if the science is preliminary, this is a creditable attempt to quantify the limitations of our existence on Earth, and provides a good basis for discussion and future refinement. To facilitate that discussion, Nature is simultaneously publishing seven commentaries from leading experts that can be freely accessed at Nature Reports Climate Change (see http://tinyurl.com/planetboundaries).

Defining the limits to our growth and existence on this planet is not only a grand intellectual challenge, it is also a potential source of badly needed information for policy-makers. Such numerical values, however, should not be seen as targets. If the history of environmental negotiations has taught us anything, it is that targets are there to be broken. Setting limits that are well within the bounds of linear behaviour might therefore be a wiser, if somewhat less dramatic, approach. That would still give policy-makers a clear indication of the magnitude and direction of change, without risking the possibility that boundaries will be used to justify prolonged degradation of the environment up to the point of no return.

\section{Biobanks need pharma}

\section{Which is why Europe's citizens need reassurance that their donations will be in the public interest.}

M edical geneticist Thomas Meitinger remembers when biobanking was a simple craft. As a postdoc thirty years ago, he travelled from Oxford to Yugoslavia to track down a family afflicted with a rare disease causing blindness. The family listened enthusiastically as he explained his research over a fish dinner. He returned with blood samples and over the next decade used them to identify the single gene defect that caused the condition.

Biobanking - collecting tissue or body fluids alongside medical information - is now a large-scale affair. Genomics allows geneticists to track down not just the single genes that convey a strong risk of disease, but also the many low-risk genes associated with the diseases that kill most of us, such as cancer, diabetes and cardiovascular disease. But these very weak gene signals can be picked up only in studies of large populations of up to hundreds of thousands of people.

Europe leads the world in biobanking. It has more than 400 biobanks, some involving hundreds of thousands of diseased and healthy individuals. It is now seeking to make the most of that resource: the European Commission is funding a preparatory study aimed at linking the biobanks into one distributed infrastructure. Now Meitinger, who currently works at the Institute of Human Genetics in Neuherberg, Germany, and the rest of the scientific consortium driving the effort, called the Biobanking and Biomolecular Resources Research Infrastructure (BBMRI), must find stable funding for the project and arrange access for the scientific community.

That's a lot of tough challenges at a time when the general public is sensitive to any issue involving genes and biological material. Key concerns in biobanking are those of anonymity and whether true informed consent can be given by individual donors now too numerous to be educated over dinner.
Another, potentially incendiary, issue is whether the pharmaceutical industry should have the same access rights to biobanks as academic researchers. Europe's citizens could easily turn against biobanking if they start to feel exploited for financial gain. The BBMRI must accommodate industry while avoiding such a backlash.

Biobank resources may be fundamental to understanding the molecular bases of common complex diseases, but it is the pharmaceutical industry that will develop the treatments for such ailments. Companies generate their own biobanks, but these cannot reach the scale necessary to move forward. Industry wants access to large public biobanks, and the BBMRI recognizes its obligation to facilitate new medicines. The consortium hopes that relentless outreach and appropriate control of banked materials will achieve this without antagonizing the public.

At the consortium's first stakeholder meeting last week, patient groups declared that they don't care who gets hold of their diseased tissue "so long as it is out of our bodies and being used to do clinical good". But the large majority of healthy donors will need more persuading that profit-making industry should get access to their voluntary tissue donations.

The concept of expert centres, unveiled by the BBMRI at the meeting, should help. These would do all the molecular analyses on material requested for an approved study and provide data only to clients. Donors' material would not move out of the biobanking infrastructure, and data would be stored for re-use in other studies, so industry could not gain exclusive rights.

Industry must also be prepared to give something back, in the form of access to its own biobanks and their richly financed expertise. Research departments across all companies believe that biobanks and the molecular information generated from them are outside the competitive realm, but their managers tend to be wedded to secrecy. So managers must be persuaded to follow their researchers' instincts, before the public gets the idea that industry is there only to exploit, gets deterred from donating, and the whole enterprise becomes tainted with distrust. 